\title{
Analysis of Genetic Variability and Agronomic Performance of Indian Lettuce (Lactuca Indica Linn.)
}

Bal Kumari Oliya ( $\sim$ balkumarioliya1@gmail.com )

Global Centre for Research and Development

Moon Young Kim

Seoul National University College of Agriculture and Life Sciences

Jungmin $\mathrm{Ha}$

Seoul National University College of Agriculture and Life Sciences

Suk Ha Lee

Seoul National University College of Agriculture and Life Sciences

\section{Research Article}

Keywords: Medicinal plant, plant breeding, genetic diversity, phenotypic traits, SSR marker

Posted Date: August 11th, 2021

DOI: https://doi.org/10.21203/rs.3.rs-735252/v1

License: () (1) This work is licensed under a Creative Commons Attribution 4.0 International License. Read Full License

Version of Record: A version of this preprint was published at Genetic Resources and Crop Evolution on November 29th, 2021. See the published version at https://doi.org/10.1007/s10722-021-01306-1. 


\section{Abstract}

Lactuca indica is a undomesticated medicinal crop in the Asteraceae family. Present study was carried out to identify elite genotype for cultivation and breeding improvement of lettuce. Data was recorded for 19 morphological and developmental traits across 38 accessions (Acc). In addition to this, the morphological cluster was compared with the simple sequence repeat (SSR) marker. The genotypic mean square variance was significant for all characters. The higher extent of genotypic and phenotypic coefficient of variation obtained for basal branch, leaf blade width, and node number. The broad-sense heritability $\left(\mathrm{H}^{2} \mathrm{~B}\right)$ ranged from $45.85 \%$ (seed length) to $98.59 \%$ (node number), whereas genetic advance as a percentage of the mean (GAM\%) ranged from 9.33 to 191 . Vegetative characters such as node number, plant hight, basal branch were conjugated with high $\mathrm{H}^{2} \mathrm{~B}$ and high $\mathrm{GAM} \%$ indicating additive gene effect and selection of these traits based on phenotypic observation is effective for better gain. Reproductive traits, including bolting duration, flowering duration, and seed weight were linked with high $\mathrm{H} 2 \mathrm{~B}$, and moderate $\mathrm{GAM} \%$ trevealing that these traits are amenable to genetic improvement, these traits also showed a significant positive correlation. Acc 55 and 8 showed the best performance for the majority of the attributes could be good material for further research and breeding. In the Wards' phylogenetic tree of morphological traits, accessions were clustered based on their phenotypic characters rather than the geographic origin. Morphological characteristics showed no or very week corelation with the SSR genotyped data.

\section{Introduction}

Breeders have been interested in searching the trait of high economic value in wild crops to improve cultivated one (Dempewolf et al., 2017). This crop improvement approach has much importance because it improves the cultivated crops and studies the possibility of cultivation of wild crops for many aspects, for instance, building the new cultivar with high yield potential and better adaptation to the biotic and biotic abiotic stress factor. A better knowledge of phenotypic variation, genetic variability, and diversity among the available germplasm and genotype is necessary (Bhattarai, Louws, Williamson, \& Panthee, 2016; Chowdhury, Vandenberg, \& Warkentin, 2002; Dempewolf et al., 2017; Ojuederie, Balogun, Fawole, Igwe, \& Olowolafe, 2014; Z. Zhang et al., 2018).

Indian lettuce (Lactuca indica Linn) is an important oriental medicinal species of the family Asteraceae. The plant is an annual or perennial, erect, lactiferous herb, with radical rosette when young, up to $2 \mathrm{~m}$ tall when flowering. Self-fertilization is common in $L$. indica, although insects visit the inflorescences, and the possibility of cross-pollination does occur. It is diploid with $2 n=2 x=18$ chromosomes and was originated in Africa (South Africa, Mozambique, Madagascar, Mauritius, Seychelles) and widespread in Asian countries probably by Chinese immigrants and relatively common to Indonesia, Malaysia, China, Taiwan, Japan, and Korea (Jeffrey, 1966; Oliya, Kim, \& Lee, 2018). Moreover, it grows in East Himalaya (Darjeeling, Arunachal Pradesh), Tibetan plateau, Assam, Burma, North Asia (Siberia, Russia, Far East), and South East Asia (Ohwi, 1984). It can be cultivated from the lowlands up to $2000 \mathrm{~m}$ altitude. The common mean of propagation is by seed, which germinates 3-4 days after sowing. Seed is usually sown in soil-bed at the end of April to early May and then transplanted in the field after 3-4 weeks. It is used traditionally in the form of soup and salad and homemade medicine to treat fever, cough, cold, diabetes and stomach disorder (Lin \& Kan, 1990). Many studies proved that this plant is an essential source in pharmaceutical and health functional foods because of the anti-oxidant, anti-inflammatory, cytotoxic, hepatoprotective, anti-bacterial, anti-diabetic, digestive, diuretic, necrotic, and sedative properties of the plant (Bown, 1995; Choi, Eom, \& Kim, 2016; K. H. Kim, Kim, \& Lee, 2007; Seo, Yang, Kays, Lee, \& Park, 2009; Wang et al., 2003). The plant is rich in nutritional compositions, phenolic compound, flavonoids, and sesquiterpene lactones (Ha et al., 2017; J.-M. Kim, Kim, Lee, Shin, \& Yoon, 2012; J. M. Kim \& Yoon, 2014; Michalska et al., 2009; Nishimura et al., 1986). Moreover, the properties such as enrichment of biotic and abiotic stress-responsive genes, wide molecular base and resistance to Downey mildew are reported for this plant (Ha et al., 2017; Oliya et al., 2018; Van Treuren, Van der Arend, \& Schut, 2013).

Among the various species in the genus Lactuca, L. sativa is the only cultivated. The success of domestication of lettuce depends on the amount of latex content, low or absent of leaf and stem spines, bigger seed size, non-shuttering seed, shortening of internodes, bunching of leaves and selection for late bolting (A. Lebeda et al., 2009; Mou, 2011). Therefore, investigating morphological characters on wild lettuce is important for lettuce breeding. To the best of our knowledge, very little information was reported for morphological characters, and no studies have made for genetic variability and agronomic analysis using morphological traits for $L$. indica. Therefore, the objective of the present study was to investigate morphological characteristics for analyzing genetic variability and agronomic performance across $L$. indica accessions. In addition, this study also aimed to elucidate genetic relationships among 38 accessions collected across Korea using morphological and simple sequence repeat (SSR) genotyped data, which was published in our previous paper (Oliya et al., 2018).

\section{Materials And Methodology Plant materials}

This study uses the same plant material used in the earlier study by Oliya et al. (2018). However, the analysis of morphological traits requires many replications from each accession to achieve a quality result. In an earlier study, we used 73 accessions from 41 collection sites; nevertheless, for this study, we only used 38 accessions covering 38 collections (Table S2-1). We excluded the remaining 29 accessions because of the unavailability of replications (because of germination failure) and three accessions because of faliure of the reproductive phase. The studied accessions have different areas of origin characterized by different geographical and ecological characteristics (Table S1). The field experiment was conducted in Seoul National University experimental farm, Suwon, the Republic of Korea (N 37 $16^{\prime} 12.094^{\prime \prime}$, E 126 59' 20.756") in 2016. Randomized complete block design with three replicates was used. In each replication (block), four competitive plants were randomly selected and tagged.

\section{Data Collection}

Visual observation for leaf shape variation, (incision of lobe) was performed at the flowering time by following the standard evaluation system for wild lettuce (Doležalová, Křístková, Lebeda, \& Vinter, 2002). Individuals were categorized, and other notable variations such as anthocyanin pigmentation, leaf margin, and inflorescence were noted. For the quantitative traits, a total of nineteen characteristics was recorded as follows: at fifty percentage flowering stage, leaf length Loading [MathJax]/jax/output/CommonHTML/fonts/TeX/fontdata.js e number (LOB); at harvest maturity, basal branching (BB), total branching (TB), plant height (PH) 
basal stem diameter (BSD), total node number (TNN) basal internode distance (BIND), median internode distance (MIND); developmental stage: seeding to bolting duration (BOLT), seeding to first flowering time (FFD), seeding to first fruit set duration (FSD), seeding to fifty percent seed maturity duration (FMD); seed per capitulum (head) (SPC), seed length (SL), pappus length (PL) and thousand seed weight (TSW).

\section{Data analysis}

The data collected for nineteen quantitative characters were subjected to analysis of variance (ANOVA) using the statistical software R. The phenotypic variance (PV) and genotypic variance (GV) were estimated based on formula given by Syukur, Sujiprihati, and Yunianti (2012). The phenotypic (PCV) and genotypic coefficient of variation (GCV) were computed by formula suggested by Burton (1952). The coefficient of variation was determined as an indicator of variability. Heritability in a broad sense $\left(\mathrm{H}^{2} \mathrm{~B}\right)$ was calculated using formula given by Allard (1960). Similarly, genetic advance (GA) was determined as described by (Johnson, Robinson, \& Comstock, 1955) and the genetic advance as a percentage of the mean (GAM), also called genetic gain was calculated as described by Johnson et al. (1955). The formula used for calculation is given in Supplementary Table 1.

For visualization of phenotypic distribution, box and whisker plot was performed using SPSS version 23 , from which the outlier can be taken as the essential accession for a particular trait. For the attribute which did not show the outlier, the accession with maximum or minimum value (based on the economic importance of each attribute) were plotted near the whisker in its approximate value scale. Again, to quantify accessions that fit the maximum traits, the quartile distribution was performed in MS- excel, from which few accessions throughout the range of characteristics can be screened. The simple correlation coefficients between the characters were calculated using the Pearson correlation coefficient using SPSS version 23.

The principal component analysis (PCA) for morphological attributes was performed using a MS-excel add-in statistical package (trial version of XLSTAT-2018 downloaded from https://www.xlstat.com/en/download). Scatter plots of the first two principle components (PCs) were estimated using the same software. The phylogenetic tree was computed using the Ward method based on the distance between the individuals constructed by Euclidean coefficients (Ward 1963).

\section{Results}

\section{Morphological characterization}

Out of total 38 accessions, ten accessions (acc. 16,19,32,46,58,59, 64, 69, and 70 were heterozygous within the accessions, others were homozygous (Table S1, Fig. S1). Individuals were categorized following the leaf type category proposed by Doležalová et al. (2002) for wild lettuce. In our samples, lobed leaf (96.93\%) was dominating over entire (3.07\%). Four leaf groups pinnatifid (73.45\%), pinnatisect (17.41\%), pinnatilobed (3.07\%) and pinnatipart (2.63) (Fig. 1) were observed. Individuals showed entire, dentate, undulating, and undulating with slight dentate margin. Among them, undulating with slight dentate type was the most common. Significant variability was recorded in anthocyanin pigmentation in rosette leaves and stems, but such variation was less during the flowering stage. Except individuals belonging to three accessions (acc. 32, 51, 70) other showed dense anthocyanin distribution in the involucre bract at the full flowering and seed setting stage, where two patterns, namely spot and stripes, existed. Two types of inflorescence, pyramidal panicles (in most individuals) and compound corymbs panicles, were observed only in three individuals belonging to acc. no 8 .

\section{Analysis of variance and variability component}

The individuals showed a considerable degree of variation in all traits studied (Table 1). In ANOVA analysis, the genotypic mean square variance for all traits was significant. Among the nineteen attributes studied, sixteen were significant at $P=0.001$, two characteristics, $P L$, and TSW were significant at $P=0.01$, and only one trait, SL, was significant at $\mathrm{P}=0.05$ (Table 1). This high morphological variation with a considerable difference between them revealed substantial genetic variability in our accessions. 
Table 1

Different characters used, abbreviations, range, mean, standard deviation and analysis of variance for different quantitative

\begin{tabular}{|c|c|c|c|c|c|}
\hline Traits & Abbreviations & Range & Mean \pm SD & $M^{2}$ & MSE \\
\hline \multicolumn{6}{|l|}{ At flowering } \\
\hline Leaf length (cm) & LL & $9.53-31.00$ & $25.09 \pm 4.10$ & $49.97 * \star \star$ & 3.86 \\
\hline Leaf tip length (cm) & LTL & $0.13-21.07$ & $8.06 \pm 4.17$ & $51.76^{\star \star \star}$ & 3.07 \\
\hline Leaf blade width (cm) & LBW & $0.52-5.67$ & $1.73 \pm 1.05$ & $3.24^{\star \star \star}$ & 0.17 \\
\hline Leaf lobe number & LOB & $0.00-6.33$ & $4.26 \pm 1.39$ & 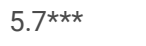 & 1.2 \\
\hline \multicolumn{6}{|l|}{ At harvest maturity } \\
\hline Total branch (number) & TB & $16.17-50.33$ & $28.68 \pm 6.94$ & $137.75^{\star \star \star}$ & 47.64 \\
\hline Plant height (cm) & $\mathrm{PH}$ & $94.33-190.28$ & $143.50 \pm 25.11$ & 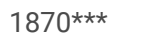 & 144 \\
\hline Basal stem diameter (cm) & BSD & $2.00-6.68$ & $4.06 \pm 1.04$ & $3.22^{\star \star \star}$ & 0.95 \\
\hline Total node number & TNN & $77.00-287.22$ & $72.62 \pm 40.05$ & $4753^{\star \star \star}$ & 67 \\
\hline Basal branch (number) & BB & $0.00-7.00$ & $1.61 \pm 1.71$ & $8.67 \star \star \star$ & 1.06 \\
\hline Basal internode distance $(\mathrm{cm})$ & BIND & $0.22-3.00$ & $1.53 \pm 0.71$ & $1.51^{\star \star \star}$ & 0.2 \\
\hline Median internode distance (cm) & MIND & $0.42-5.13$ & $3.28 \pm 1.07$ & $3.38^{\star \star \star}$ & 0.26 \\
\hline \multicolumn{6}{|l|}{ Developmental stage } \\
\hline Duration to bolting (days) & BOLT & $87.00-122.14$ & $108.86 \pm 8.06$ & $192.46^{\star \star \star}$ & 40.44 \\
\hline Duration to first flowering (days) & FFD & 105.33-141.42 & $125.33 \pm 9.69$ & $277.9 * \star \star$ & 40.6 \\
\hline Duration to first seed set (days) & FSD & $110.33-149.42$ & $132.31 \pm 10.41$ & 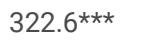 & 35.9 \\
\hline Duration to fifty percent seed maturity (days) & FMD & 119.94-160.08 & $142.91 \pm 11.36$ & $382.5^{\star \star \star}$ & 74.8 \\
\hline \multicolumn{6}{|l|}{ Seed } \\
\hline Seed per capitulum (head) & SPC & $14.40-28.53$ & $22.1 \pm 3.35$ & $33.65^{\star \star \star}$ & 9.82 \\
\hline Seed length (cm) & $\mathrm{SL}$ & $0.31-0.46$ & $0.38 \pm 0.04$ & $0.01^{*}$ & 0.003 \\
\hline Pappus length (cm) & PL & $0.69-0.95$ & $0.85 \pm 0.07$ & $0.01^{\star \star}$ & 0.006 \\
\hline Thousand seed weight (gm) & TSW & $0.63-2.38$ & $1.12 \pm 0.45$ & $0.61^{\star *}$ & 0.32 \\
\hline
\end{tabular}

To compare the variation among morphological traits, the variability components, PV, GV, PCV, GCV, H²B, GA and GAM\% estimated for 19 quantitative characters were presented in Table 2. The highest and lowest GV and PV was obtained for TNN and TSW, respectively. GCV ranged from 6.11 to 99.12\%, and PCV ranged from 7.36 to $105.77 \%$. In general, PCV was found higher than GCV for all traits. BB showed the highest value for GCV and PCV; however, PL and BOLT resembled the lowest value. According to (Deshmukh, Basu, \& Reddy, 1986), the estimate of GCV and PCV values greater than $20 \%$ is high and values between $10 \%$ and $20 \%$ to be medium, whereas values less than $10 \%$ are considered to be medium be low. In the present study, lower GCV and PCV values were recorded for BOLT, FFD, FSD, FMD, and PL, indicating the influence of the environment on trait expression. Other traits were moderate to high for GCV and PCV, indicating less influence of environment for expressing these traits. The highest and lower genotypic and phenotypic variation was obtained for TNN and TSW, respectively. GCV ranged from 6.11 to $99.12 \%$, and PCV ranged from 7.36 to $105.77 \%$. According to Dabholkar (1999), heritability estimates can be low, ranging from 5 to $30 \%$; medium ranging from 30 to $60 \%$; and high ranging from $60 \%$ to above. From this point of view, the broad-sense heritability estimates were medium for SL, PL, TSW, and high for other traits, with TNN (98.59\%) showing the highest and SL (45.85\%) delivering lowest value. The genetic advance ranged from $0.08(\mathrm{PL})$ to 80.84 (TNN). Genetic advance as a percentage of the mean (GAM\%) ranged from 9.33\% (PL) to $191.35 \%(B B)$. The GAM\% can be categorized according to (Johnson et al., 1955) as low (<10\%), moderate (10-20\%) and high (>20\%). In this context, GAM\% was low for SL and PL, moderate for BOLT, FFD, FSD, FMD, SL, and high for other traits. The top three genetic gains were obtained for BB (191.35\%) followed by LBW (117.04\%) and TNN (191.35\%) (Table 2). For obtaining the idea about expected genetic gain in next-generation, heritability has to be considered in conjugation with genetic gain/genetic advance as a percentage of the mean (Johnson et al., 1955). Traits such as LL, LTL, LBW, LOB, TB, PH, BSD, TNN, BB, BIND, and MIND showed high heritability associated with increased genetic gain. For other traits, BOLT, FFD, FSD, FMD, and SPC, which showed high heritability was in conjugation with moderate genetic gain, similarly, SL and TSW with moderate heritability was associated with average genetic gain and PL with moderate heritability was linked with low genetic gain (Table 2) 
Table 2

Estimate of genetic parameters for evaluated traits in L. indica

\begin{tabular}{|c|c|c|c|c|c|c|c|}
\hline Characters $^{x}$ & GV & PV & GCV \% & PCV \% & $\mathrm{H}^{2} \mathrm{~B} \%$ & GA & GAM\% \\
\hline LL & 15.47 & 16.66 & 15.63 & 16.27 & 92.28 & 7.76 & 30.92 \\
\hline LTL & 16.23 & 17.25 & 49.96 & 51.51 & 94.07 & 8.05 & 99.82 \\
\hline LBW & 1.02 & 1.08 & 58.37 & 59.96 & 94.75 & 2.03 & 117.04 \\
\hline LOB & 1.50 & 1.90 & 28.71 & 32.32 & 78.92 & 2.24 & 52.54 \\
\hline TB & 30.04 & 45.92 & 19.11 & 23.63 & 65.42 & 9.13 & 31.84 \\
\hline $\mathrm{PH}$ & 575.33 & 623.33 & 16.72 & 17.40 & 92.30 & 47.47 & 33.08 \\
\hline BSD & 0.76 & 1.07 & 21.46 & 25.53 & 70.64 & 1.51 & 37.15 \\
\hline TNN & 1562 & 1584.33 & 54.42 & 54.81 & 98.59 & 80.84 & 111.31 \\
\hline BB & 2.54 & 2.89 & 99.12 & 105.77 & 87.82 & 3.08 & 191.35 \\
\hline BIND & 0.43 & 0.50 & 43.23 & 46.47 & 86.55 & 1.26 & 82.85 \\
\hline MIND & 1.04 & 1.13 & 31.08 & 32.34 & 92.36 & 2.02 & 61.52 \\
\hline BOLT & 50.67 & 64.15 & 6.54 & 7.36 & 78.99 & 13.03 & 11.97 \\
\hline FFD & 79.10 & 92.63 & 7.10 & 7.68 & 85.39 & 16.93 & 13.51 \\
\hline FSD & 95.57 & 107.53 & 7.39 & 7.84 & 88.87 & 18.98 & 14.35 \\
\hline FMD & 102.57 & 127.5 & 7.09 & 7.90 & 80.44 & 18.71 & 13.09 \\
\hline SPC & 7.94 & 11.22 & 12.75 & 15.15 & 70.82 & 4.89 & 22.11 \\
\hline SL & 0.001 & 0.002 & 7.34 & 10.84 & 45.85 & 4.00 & 10.24 \\
\hline$P L$ & 0.003 & 0.005 & 6.11 & 8.25 & 54.85 & 0.08 & 9.33 \\
\hline TSW & 0.09 & 0.20 & 27.54 & 39.97 & 47.49 & 0.44 & 39.10 \\
\hline \multicolumn{8}{|c|}{$\begin{array}{l}\text { xLL: leaf length, LTL: leaf tip length, LBW: leaf blade width, LOB: leaf lobe number; BB: basal branch, TB: total branch, PH: plant height, BSD: basal stem } \\
\text { diameter, TNN: total node number, BIND: basal internode distance, MIND: median internode distance, BOLT duration to bolting, FFD: duration to first } \\
\text { flowering, FSD: duration to first seed set, FMD: duration to fifty percent seed maturity, SPC: seed per capatilium, PL: pappus length, SL: seed length, TWS } \\
\text { thousand seed weight, GV: genotypic variance, PV: phenotypic variance, GCV: genotypic coefficient of variance, PCV, phenotypic coefficient of variance, } \\
\mathrm{H}^{2} \mathrm{~B} \text { : broad sense heritability, GA: genetic advance, GAM: genetic advance as percentage of mean. }\end{array}$} \\
\hline
\end{tabular}

\section{Quantification of potential accessions}

Box and whisker plots were used to visualize distributions of values for each trait across the accessions. The line within the box represents the median, the box range includes the second and third quartile, and the whiskers represent the minimum-maximum values. The outliers are described in the hallowed circle and the star. The Box-whisker plot of agronomic performance showed the distribution of accessions within the interquartile range for most traits; however, some accessions distributed in the form of outliers. (Fig. 2). Moreover, to quantify the best performing accessions throughout the range of traits, we plotted them into the quartile distribution, and quartile member sets were identified based on the economic importance of agronomic traits. Higher values were expected for all traits except LTL, LOB, BIND, and MIND, where a lower value is considered best for more significant economic gain. Thus, the fourth quartile for high measuring traits and first quartile for low measuring traits were taken. With this assumption, two accessions acc. 8 and 55 were found superior whose overall trait value in the fourth quartile were 12 and 11, respectively (Table S2). These accessions could be good breeding material (Fig. 2)

\section{Correlation analysis}

The Pearson correlation coefficients between traits are presented in Table 3. LL showed significant positive correlation with $L T L(r=0.462, P<0.01)$, and significant negative correlation with LOB $(r=-0.373, P<0.05)$. BB showed negative correlation with LOB $(r=-0.325)$ and BIND ( $r=-354)$; however, the correlation of BB was positive with PL $(r=0.389)$. The correlation of TB with BSD and TNN was $r=0.573$ and 0.36 , respectively. PH was positively correlated with BSD ( $r=$ $0.495, P<0.001)$, TNN $(r=0.363, P<0.05)$ and SPC $(r=0.326, P<0.05)$. In addition, TNN showed strong negative correlation with BIND $(r=-0.439)$ and MIND $(r=-0.453)$ but the correlation with TB, PH and BSD was positive $(r=0.361,0.363$ and 0.459 , respectively). Interestingly, the reproductive traits such as BOLT, FFD, FSD and FMD were strongly positively correlated with each other, however these traits showed no correlation with other traits. Where the correlation of BOLT with FF ( $r=0.92)$, FSD $(r=0.896)$ and SMD $(r=0.827)$. Similarly, correlation of FSD with FFD $(r=0.967)$ and FMD ( $r=0.922)$ and FMD with FSD was $(r=$ 0.936). PL showed certain positive correlation with TB and SL (correlation of PL with TB and $S L=0.389$ and 0.383 at $p=0.05$ ) and TSW showed no correlation with any of the traits studied (Table 3). 
Table 3

Coefficient of correlation among the morphological characters in the studies accessions of L. indica

\begin{tabular}{|c|c|c|c|c|c|c|c|c|c|c|c|c|c|c|}
\hline Traits $^{x}$ & LL & LTL & LBW & LOB & TB & $\mathrm{PH}$ & BSD & TNN & BB & BIND & MIND & BOLT & FFD & FSD \\
\hline LL & 1.00 & & & & & & & & & & & & & \\
\hline LTL & $0.462^{\star *}$ & 1.00 & & & & & & & & & & & & \\
\hline LBW & -0.219 & -0.021 & 1.00 & & & & & & & & & & & \\
\hline LOB & $-0.373^{*}$ & -0.162 & 0.206 & 1.00 & & & & & & & & & & \\
\hline TB & -0.206 & 0.162 & -0.274 & -0.093 & 1.00 & & & & & & & & & \\
\hline $\mathrm{PH}$ & 0.270 & 0.177 & -0.071 & -0.077 & 0.240 & 1.00 & & & & & & & & \\
\hline BSD & 0.244 & 0.231 & $-0.410^{*}$ & 0.078 & $0.573^{\star *}$ & $0.495^{\star *}$ & 1.00 & & & & & & & \\
\hline TNN & 0.187 & 0.125 & -0.099 & 0.029 & $0.361^{\star}$ & $0.363^{*}$ & $0.459^{\star *}$ & 1.00 & & & & & & \\
\hline BB & 0.124 & -0.134 & -0.222 & $-0.325^{*}$ & 0.097 & -0.159 & 0.000 & 0.213 & 1.00 & & & & & \\
\hline BIND & -0.248 & -0.008 & 0.062 & 0.236 & 0.158 & -0.185 & -0.084 & $-0.439 * *$ & $-0.354^{\star}$ & 1.00 & & & & \\
\hline MIND & 0.082 & 0.023 & -0.009 & -0.129 & -0.199 & 0.179 & -0.192 & $-0.453^{\star \star}$ & -0.168 & 0.183 & 1.00 & & & \\
\hline BOLT & 0.086 & -0.176 & 0.082 & -0.059 & -0.046 & 0.047 & 0.029 & 0.265 & -0.078 & -0.212 & -0.291 & 1.00 & & \\
\hline FFD & 0.042 & -0.117 & 0.215 & -0.078 & -0.098 & 0.090 & -0.014 & 0.229 & -0.120 & -0.258 & -0.216 & $0.927^{\star *}$ & 1.00 & \\
\hline FSD & 0.040 & -0.089 & 0.205 & -0.105 & -0.109 & 0.104 & -0.001 & 0.185 & -0.141 & -0.245 & -0.248 & $0.896 * *$ & $0.967 * \star$ & 1.00 \\
\hline FDM & 0.033 & -0.089 & 0.206 & -0.066 & -0.174 & -0.009 & -0.105 & 0.181 & -0.013 & -0.253 & -0.151 & $0.827^{\star *}$ & $0.922^{\star *}$ & 0.936 ** \\
\hline SPC & 0.134 & 0.105 & -0.140 & 0.212 & -0.122 & $0.326^{\star}$ & 0.248 & 0.175 & -0.130 & -0.189 & -0.058 & 0.143 & 0.114 & 0.110 \\
\hline$S L$ & 0.052 & 0.179 & -0.015 & -0.119 & 0.031 & -0.272 & -0.029 & -0.060 & 0.105 & -0.044 & -0.014 & -0.095 & 0.002 & -0.002 \\
\hline PL & 0.259 & 0.268 & -0.061 & -0.225 & -0.033 & -0.153 & 0.031 & 0.013 & $0.389^{*}$ & -0.308 & -0.110 & -0.099 & -0.138 & -0.124 \\
\hline TSW & 0.166 & 0.060 & 0.029 & -0.192 & -0.072 & 0.172 & 0.009 & 0.163 & -0.171 & -0.208 & 0.226 & 0.280 & 0.255 & 0.183 \\
\hline
\end{tabular}

${ }^{*}$ Correlation is significant at 0.05 and ${ }^{* *}$ correlation is significant at 0.01 level.

xLL: leaf length, LTL: leaf tip length, LBW: leaf blade width, LOB: leaf lobe number, BB: basal branch, TB: total branch, PH: plant height, BSD: basal stem diam internode distance, MIND: median internode distance; BOLT: duration to bolting, FFD: duration to first flowering, FSD: duration to first seed set, FMD: duration capitulum (head), SL: seed length, PL: pappus length, TWS: thousand seed weight.

\section{Principal component analysis (PCA)}

In the PCA, $64 \%$ of total phenotypic variation was explained by first five components (Table 4). The first component (PC1) accounted for $22.09 \%$ of phenotypic variation where the reproductive traits such as BOLT, FFD, FSD, FMD have high loading. The second component (PC2) explained an additional 15.29\% phenotypic variation, which was featured by BSD, PH, TB, and TNN. Similarly, LOB accounted for the highest score in the third component (PC3), which covered an additional $11.86 \%$ of phenotypic variation. The principal component fourth (PC4) and five (PC5) accounted for additional $9.65 \%$ and $7.11 \%$ of the phenotypic variation. The highest eigenvalue was covered by PC1 (4.20) in decreasing order followed by PC2, PC3, PC4, and PC5, respectively (Table 4). 
Table 4

Principal component analysis for 19 quantitative traits across $38 \mathrm{~L}$. indica

\begin{tabular}{|lccccc|}
\hline Traits & PC1 & PC 2 & PC 3 & PC 4 & PC 5 \\
\hline Leaf length & 0.06 & 0.31 & -0.21 & 0.36 & -0.09 \\
\hline Leaf tip length & -0.04 & 0.27 & -0.08 & 0.27 & 0.28 \\
\hline Leaf blade width & 0.08 & -0.30 & -0.02 & 0.06 & 0.02 \\
\hline Lobe number & -0.05 & -0.18 & 0.37 & -0.15 & -0.15 \\
\hline Total branch number & -0.05 & 0.29 & 0.23 & -0.29 & 0.47 \\
\hline Plant height & 0.09 & 0.30 & 0.30 & 0.31 & -0.05 \\
\hline Basal stem diameter & 0.03 & 0.43 & 0.29 & -0.07 & 0.16 \\
\hline Total node number & 0.19 & 0.36 & 0.13 & -0.21 & -0.09 \\
\hline Basal branch number & -0.03 & 0.19 & -0.34 & -0.34 & -0.26 \\
\hline Basal internode distance & -0.20 & -0.24 & 0.24 & 0.03 & 0.42 \\
\hline Midian internode distance & -0.15 & -0.11 & -0.04 & 0.51 & 0.06 \\
\hline Duration to bolting & 0.45 & -0.05 & 0.02 & -0.04 & 0.06 \\
\hline Duration to first flowering & 0.47 & -0.09 & 0.00 & 0.00 & 0.10 \\
\hline Duration to first seed set & 0.47 & -0.09 & 0.00 & 0.00 & 0.11 \\
\hline Duration to 50\% seed maturity & 0.44 & -0.12 & -0.08 & -0.02 & 0.07 \\
\hline Seed per capatilium & 0.10 & 0.15 & 0.25 & 0.16 & -0.43 \\
\hline Seed length & -0.02 & 0.04 & -0.34 & -0.09 & 0.37 \\
\hline Pappus length & -0.04 & 0.20 & -0.45 & -0.07 & 0.00 \\
\hline Thousand seed weight & 0.15 & 0.07 & -0.10 & 0.34 & 0.15 \\
\hline Eigenvalue & 4.20 & 2.90 & 2.25 & 1.83 & 1.35 \\
\hline Variability (\%) & 22.09 & 15.29 & 11.86 & 9.65 & 7.11 \\
\hline
\end{tabular}

\section{Cluster analysis}

In morphological data,three different clusters, CL-I, CL-II, and CL-III, at euclidean distances of 160 were were obtained. In CL-I acc 8, 12, 36, and 37 having TNN, FF, and FSD values in Q4 in the quartile distribution clustered. Among them, acc 15,16,32,39, and 58 had TNN in Q2 (except acc 39 ) and BOLT in Q3 (except acc 58) were sub grouped. Five acc 4,7,11,51,70 had LOB in Q1, PH in Q2, and TSW in Q3 (except acc 70, Q4) were grouped. In CL-II, 13 acc with FMD in Q1 (except acc 65), LBW in Q3 (except ac6), BOLT, and FF in Q1, Q2 were closed. In CL-III, a total of 10 acc having values in Q1 for PH, NN, LTL, TB, FF, FSD were clusterd together in this cluster two acc45, and 54 with LTL, LBW, FF, FSD, FMD values distributed in Q1 were closed. Interestingly, one accession (acc. 55) isolated in the form of an outlier had showen better performance for 11 traits with higher economic value out of 19 traits (Fig. 4A). The apparent clustering of accessions according to the geographical origin of the collection was absent. In the SSR marker-based UPGMA tree, two clusters could be visualized. All accessions from Central-Northern province Gangwon, Gyeonggi and Chungbuk (except acc.25) were grouped in Cl-I, and acc from Southern Jeonnam (except acc.65) Jeonbuk lies in CL-II. Other acc from Central province Chungnam, Gyeobbuk, and Gyeongnam distributed in both clusters, but acc did not correlate with their morphology (Fig. 4B).

\section{Discussions}

$L$. indica is one of the potential wild lettuce with high nutraceutical, therapeutic and breeding potential. The assessment of genetic diversity and agronomic performance is essential which help to investigate its valuable traits, genetic structure, and better breeding material for $L$. indica production and commercialization. We found ample variability among the studied accessions using morphological (both qualitative and quantitative) characters in the present study. Among all attributes, leaf shape variation was most distinct. Leaf shape variation plays a crucial role in shaping the plants functioning and taxonomical identification (Lindqvist, 1960; Niinemets, 2015; Wright et al., 2005; Wright et al., 2004). Previously, high level of genetic diversity using genic-SSR marker data have been reported (Oliya et al. 2018). The genetic variability among $L$. indica individuals is an example of gene reshuffling, gene flow, natural selection, environmental heterogeneity, and variation in secondary metabolites. Morphological variability has been reported in other Lactuca species, including L. sativa, L. serriola, L. saligna, L. Canadensis, L. acunetia (Beharav, Ben-DAvid, Doležalová, \& Lebeda, 2008, 2010; Doležalová et al., 2002; A Lebeda et al., 2010; A. Lebeda et al., 2009; Ogbodo, Okorie, \& Utobo, 2010).

In lettuce breeding, the high variation in flowering time has economic importance because it produces a high concentration of sesquiterpene lactone at flowering time. So early flowering accessions can help speed up generation time in genetic, phytomedicinal, and growth studies (Choi et al., 2016). In contrast,

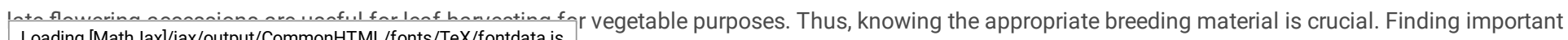


traits using genomic tools is costly for whole accessions. In this regard, the phenotypic study helps to identify the peculiar accessions for further studies (van Nocker \& Gardiner, 2014). The potential donor accessions screened in our study could be helpful in parental selection for breeding, introgression of the gene to cultivated lettuce, gene diversity, and marker-trait association studies (Uwimana et al., 2012). Significant marker-trait associations and genes responsible for anthocyanin distribution and flowering control in lettuce have been studied (Kwon, Simko, Hellier, Mou, \& Hu, 2013; Ryder \& Milligan, 2005; L. Zhang et al., 2017).

In a population, observed variation is caused by genetic and environmental factors. However, only genetic variation is inherited. Therefore estimation of heritability and genetic advance together could provide the best image of the amount of advancement to be expected through phenotypic selection (Johnson et al., 1955). In the present study, leaf blade width, total and basal branch, node number, plant height, basal and median internode distance, seed per capatilium and thousand seed weight were associated with high heritability and high genetic advance as percentage mean (GAM\%). These traits have additive gene effects, and these traits based on phenotypic observation are effective for better gain. Other characteristics, the duration for bolting, first flowering, seed set, and seed maturity having high heritability, were linked with moderate GAM\% and dispersed in the outlier in the box plot, therefore anticipated for improved productivity via hybridization and selection studies. Moreover, the significant correlation between the traits suggests that one character's selection practice may simultaneously change the other correlated character.

The method of clustering using morphological traits showed the clustering of accessions with particular morphological character rather than the geographic distribution. The clustering based on SSR genotyped data did not showed any correlation with the morphological characters ; however, genetic data was more robust to separate accessions absed on their geographic origin. This could be attributed to the influence of plant growth and development by environmental and climatic conditions. The limited correlation between the divergence of morphological traits and the data obtained using a molecular marker suggests that environmental factors and genetic factor may determine morphological variation. And the morphological characteristics are associated with a relatively small number of specific gene loci as reported for other crops (Seyedimoradi et al., 2012; Kumar et al., 2013; Jain et al., 2017). The mode of inheritance in the numerious difference between shape and size as well as architectural arrangement and orientation (also called discontinuous variation) is governed by one or two gene loci. In contrast, the classical component of agricultural yield such as plant height, dimention,weight, and number generally exhibit the continuous variation in their expression and usually governed by multiple gene system (Gottlieb 1984)

In conclusion, the high level of variability and diversity on agro-morphological traits and influence of genetic factors on trait expression appeal to researcher for the efficient utilization and improvement of $L$. indica in the lettuce breeding program. Moreover, the best accessions screened in this study could help to certified $L$. indica cultivar production and commercialization. Thus, L. indica an undomesticated medicinal crop could be the most viable option to address the issues raised on lettuce breeding, community health, and fulfillment of natural drug demand.

\section{Declarations}

\section{Acknowledgment}

\section{Compliance with ethical standards}

All co-authors of this paper declare that there is no conflict of interest.

\section{References}

Allard R. 1960. Principles of plant breeding. John Wiley New York

Beharav A, Ben-David R, Dolezalova I, Lebeda A. 2010. Eco-geographical distribution of Lactuca aculeata natural populations in northeastern Israel. Genet. Resour.Crop Evol. 57:679-686 doi:10.1007/s10722-009-9503-6

Beharav A, Ben-DAvid R, Doležalová I, Lebeda A. 2008. Eco-geographical distribution of Lactuca saligna natural populations in Israel. Isr. J. Plant Sci.56:195206

Bhattarai K, Louws FJ, Williamson JD, Panthee DR. 2016. Diversity analysis of tomato genotypes based on morphological traits with commercial breeding significance for fresh market production in eastern USA. Aus. J. Crop Sci. 10:1098

Bown D. 1995. The royal horticultural society encyclopedia of herbs \& their uses. Dorling Kindersley Limited

Burton GW. 1952. Quantitative inheritance in grasses. Proc. 6th Int. Grassland Cong. 1:227-285

Choi C-I, Eom HJ, Kim KH. 2016 Antioxidant and a-glucosidase inhibitory phenolic constituents of Lactuca indica L. Russ. J. Bioorganic Chem. $42: 310-315$.

Chowdhury M, Vandenberg B, Warkentin T. 2002. Cultivar identification and genetic relationship among selected breeding lines and cultivars in chickpea (Cicer arietinum L.). Euphytica 127:317-325.

Dabholkar A. 1999. Elements Of Biometrical genetics (revised And Enlarged Edition). Concept publishing company, New Delhi, India.

Dempewolf H, Baute G, Anderson J, Kilian B, Smith C, Guarino L. 2017. Past and future use of wild relatives in crop breeding. Crop Sci. 57:1070-1082.

Loading [MathJax]/jax/output/CommonHTML/fonts/TeX/fontdata.js 
Deshmukh S, Basu M, Reddy P. 1986. Genetic variability, character association and path coefficients of quantitative traits in Virginia bunch varieties of groundnut. Indian J. Agric. Sci. 56: 816-821

Doležalová I, Křístková E, Lebeda A, Vinter V. 2002. Description of morphological characters of wild Lactuca L. spp. genetic resources (English-Czech version). Hort. Sci. (Prague) 29:56-83

Gottlieb LD, (1984). Genetics and morphological evolution in plants. The American Naturalist, 123(5), 681-709.

Ha J, Lee T, Kim MY, Oliya BK, Gwag J-G, Lee Y-H, Lee S-h. 2017. Comprehensive transcriptome analysis of Lactuca indica, a traditional medicinal wild plant. Mol Breed 37:112 doi:10.1007/s11032-017-0711-z

Jeffrey C. 1966. Notes on the Compositae: I. The Cichorieae in East Tropical Africa. Kew Bulletin 18:427-486

Jain JR, Timsina B, Satyan KB, Manohar SH. 2017. A comparative assessment of morphological and molecular diversity among Sechium edule (Jacq.) Sw. accessions in India. 3 Biotech, 7(2):1-8.

Johnson HW, Robinson H, Comstock R. 1955. Estimates of genetic and environmental variability in soybeans. Agron. J. 47:314-318

Kim J-M, Kim J-N, Lee K-S, Shin S-R, Yoon K-Y. 2012. Comparison of physicochemical properties of wild and cultivated Lactuca indica. J. Korean Soc. Food Sci. Nutr. 41:526-532

Kim JM, Yoon KY. 2014. Comparison of polyphenol contents, antioxidant, and anti-inflammatory activities of wild and cultivated Lactuca indica. Hort. Env.Biotechnol. 55:248-255

Kim KH, Kim YH, Lee KR. 2007. Isolation of quinic acid derivatives and flavonoids from the aerial parts of Lactuca indica L. and their hepatoprotective activity in vitro Bioorg. Med. Chem. Lett. 17:6739-6743 doi:10.1016/j.bmcl.2007.10.046

Kumar S, Nair N. 2013. Genetic variation and phylogenetic relationships among Indian citrus taxa revealed by DAMD-PCR markers. Genet Resour Crop Evol. 60:1777-1800. doi: 10.1007/s10722-013-9954-7.

Kwon S, Simko I, Hellier B, Mou B, Hu J. 2013. Genome-wide association of 10 horticultural traits with expressed sequence tag-derived SNP markers in a collection of lettuce lines. Crop J. 1:25-33

Lebeda A, Dolezalová I, Kitner M, Novotná A, Smachova P, Widrlechner M. 2010. North American continent-a new source of wild Lactuca spp. germplasm variability for future lettuce breeding. In: XXVIII International Horticultural Congress on Science and Horticulture for People (IHC2010): III International Symposium on 918 , pp. 475-482

Lebeda A, Dolezalova I, Kristkova E, Kitner M, Petrzelova I, Mieslerova B, Novotna A. 2009. Wild Lactuca germplasm for lettuce breeding: current status, gaps and challenges. Euphytica 170:15-34 doi:10.1007/s10681-009-9914-7

Lin C-C, Kan W-S. 1990. Medicinal plants used for the treatment of hepatitis in Taiwan. Am.J. Chin. Med. 18:35-43

Lindqvist K. 1958. Inheritance of lobed leaf form in Lactuca. Hereditas 44:347-377

Michalska K, Stojakowska A, Malarz J, Doležalová I, Lebeda A, Kisiel W. 2009. Systematic implications of sesquiterpene lactones in Lactuca species. Biochem. Syst. Ecol. 37:174-179

Mou B. 2011. Mutations in lettuce improvement. Int. J. Plant. Genomics: 1-7

Niinemets Ü. 2015. Is there a species spectrum within the world-wide leaf economics spectrum? Major variations in leaf functional traits in the Mediterranean sclerophyll Quercus ilex. New Phytol. 205:79-96

Ogbodo E, Okorie P, Utobo E. 2010. Growth and yield of lettuce (Lactuca sativa L.) at Abakaliki agro-ecological zone of southeastern Nigeria. World J. Agri. Sci. 6:141-148

Ohwi J. 1984. Flora of Japan A combined much revised, and extended translation by the author of his Flora of Japan (1953) and Flora of Japan: Pteridophyta (1957). In: Meyer FG, Walker EH (eds) Flora of Japan. Smithsonian Inst, Washington, 461 pp.

Ojuederie OB, Balogun MO, Fawole I, Igwe DO, Olowolafe MO. 2014 Assessment of the genetic diversity of African yam bean (Sphenostylis stenocarpa Hochst ex. A Rich. Harms) accessions using amplified fragment length polymorphism (AFLP) markers. Afr. J. Biotechnol. 13

Oliya BK, Kim MY, Lee S-H. 2018. Development of genic-SSR markers and genetic diversity of Indian lettuce (Lactuca indica L.) in South Korea Genes \& genomics 40:615-623

Ryder EJ, Milligan DC. 2005. Additional genes controlling flowering time in Lactuca sativa and L. serriola. J. Am. Soc. Hort. Sci. 130:448-453

Seo MW, Yang DS, Kays SJ, Lee GP, Park KW. 2009. Sesquiterpene Lactones and Bitterness in Korean Leaf Lettuce Cultivars. Hort.Sci. 44:246-249

Loading [MathJax]/jax/output/CommonHTML/fonts/TeX/fontdata.js 
Seyedimoradi H, Talebi R, Hassani D, Karami F.2012 Comparative genetic diversity analysis in Iranian local grapevine cultivars using ISSR and DAMD molecular markers. Environ Exp Bot. 10:125-132

Uwimana B, Smulders MJM, Hooftman DAP, Hartman Y, van Tienderen PH, Jansen J, McHale LK, Michelmore RW, van de Wiel CMM, Visser RGF. 2012. Hybridization between crops and wild relatives: the contribution of cultivated lettuce to the vigour of crop-wild hybrids under drought, salinity and nutrient deficiency conditions Theor. Appl. Genet. 125:1097-1111

van Nocker S, Gardiner SE. 2014. Breeding better cultivars, faster: applications of new technologies for the rapid deployment of superior horticultural tree crops. Hort. Res. 1:14022

Van Treuren R, Van der Arend A, Schut J. 2013. Distribution of downy mildew (Bremia lactucae Regel) resistances in a genebank collection of lettuce and its wild relatives. Plant Genetic Resources 11:15-25

Wang SY, Chang HN, Lin KT, Lo CP, Yang NS, Shyur LF. 2003. Antioxidant properties and phytochemical characteristics of extracts from Lactuca indica. J. Agric. Food Chem. 51:1506-1512 doi:10.1021/jf0259415

Ward Jr, J H. 1963. Hierarchical grouping to optimize an objective function. Journal of the American statistical association, 58(301): 236-244

Wight IJ, Reich PB, Cornelissen JHC, Falster DS,Groom PK. et. al. 2005. Modulation of leaf economic traits and trait relationships by climate. Global Ecol. Biogeogr. 14:411-421

Wright IJ, Reich PB, Westoby M, Ackerly DD, Baruch Z. et. al. 2004. The worldwide leaf economics spectrum. Nature 428:821

Zhang L, Su W, Tao R, Zhang W, Chen J, Wu P, Yan C, Jia Y, Larkin RM, Lavelle D, Truco MJ. 2017. RNA sequencing provides insights into the evolution of lettuce and the regulation of flavonoid biosynthesis. Nature communications 8:2264

Zhang Z, Xie W, Zhang J, Zhao X, Zhao Y, Wang Y. 2018. Phenotype-and SSR-based estimates of genetic variation between and within two important Elymus Species in Western and Northern China. Genes 9:147

\section{Figures}
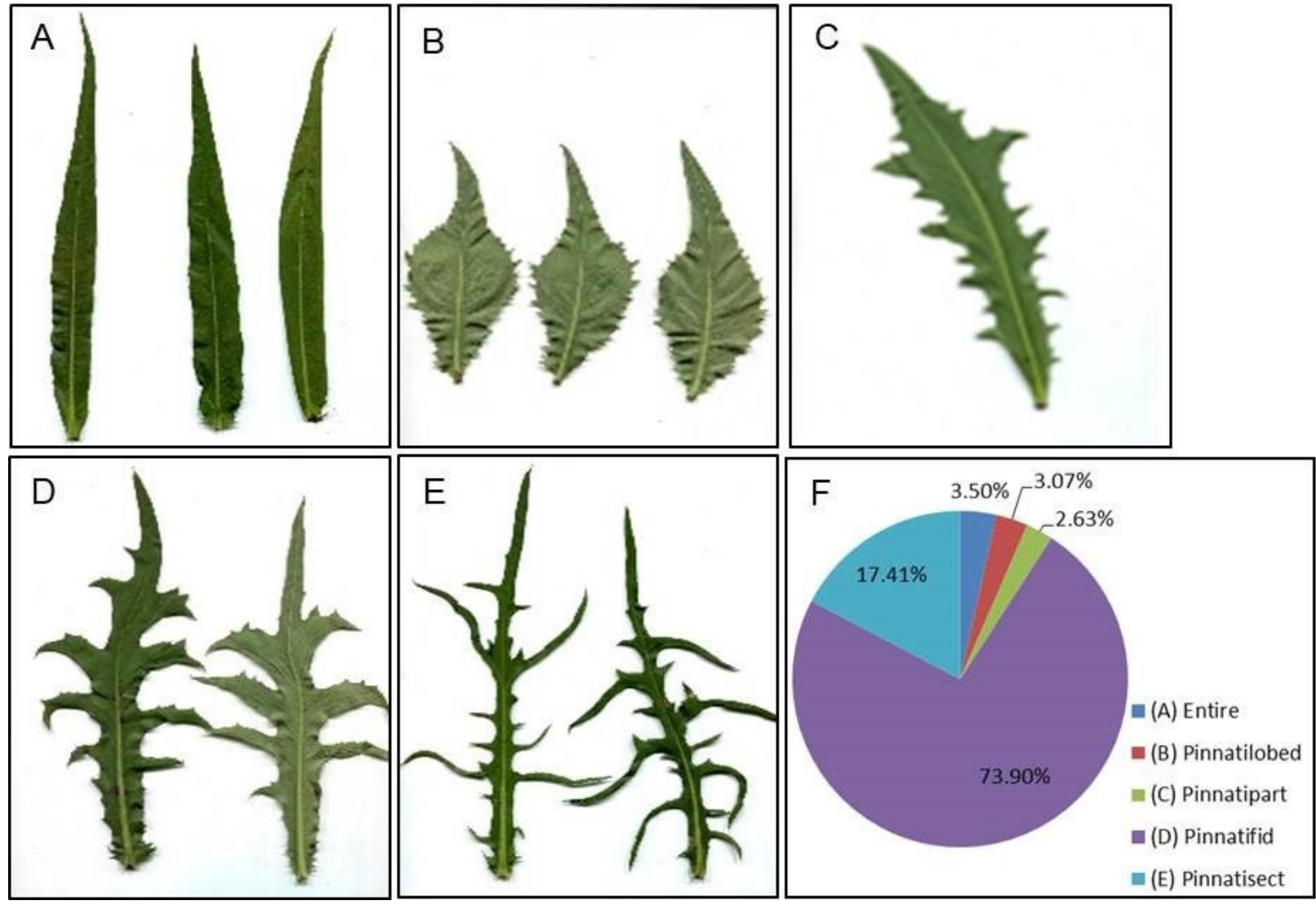

Figure 1 
Variability in leaf character for fully matured cauline leaf from the middle part of stem at a stage of full flowering of L. indica accessions collected from South Korea.
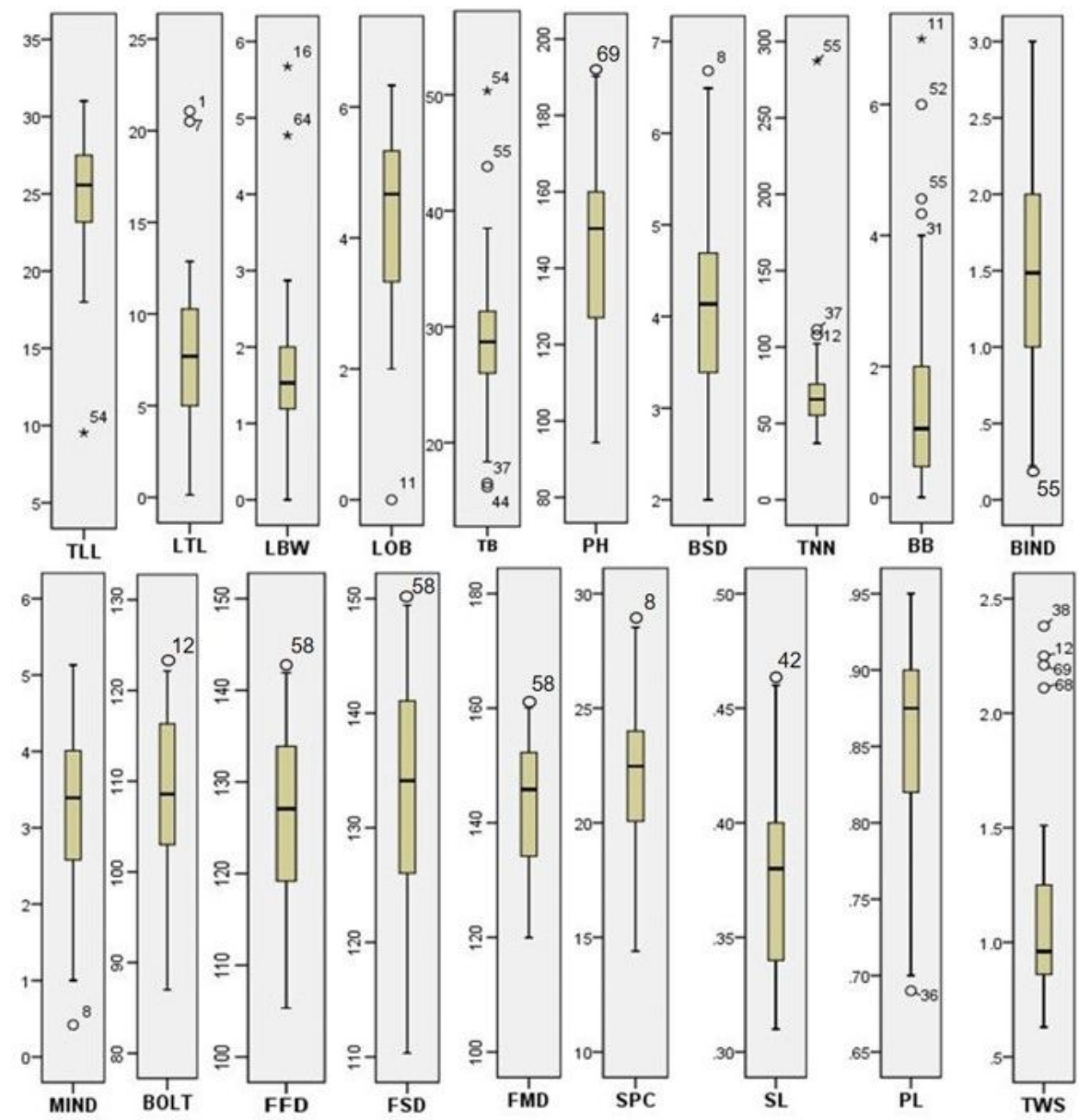

Figure 2

Box-whisker plot of agronomic performance for recorded traits observed for 38 accessions, the outlier accessions are potential donor accessions for particular trait. The black horizontal line represents the median value, the boxes represents the middle quartiles, the whiskers represents the range of data and the hallo points and stars represents the outliers. Abbreviations, LL: leaf length, LTL: leaf tip length, LBW: leaf blade width, LOB: leaf lobe number; BB: basal branch, TB: total branch, $\mathrm{PH}$ : plant height, BSD: basal stem diameter, TNN: total node number, BIND: basal internode distance, MIND: median internode distance BOLT: duration to bolting, FFD: duration to first flowering, FSD: duration to first seed set, FMD: duration to fifty percent seed maturity, SPC: seed per capatilium, PL: pappus length, SL: seed length, TWS: thousand seed weight. 

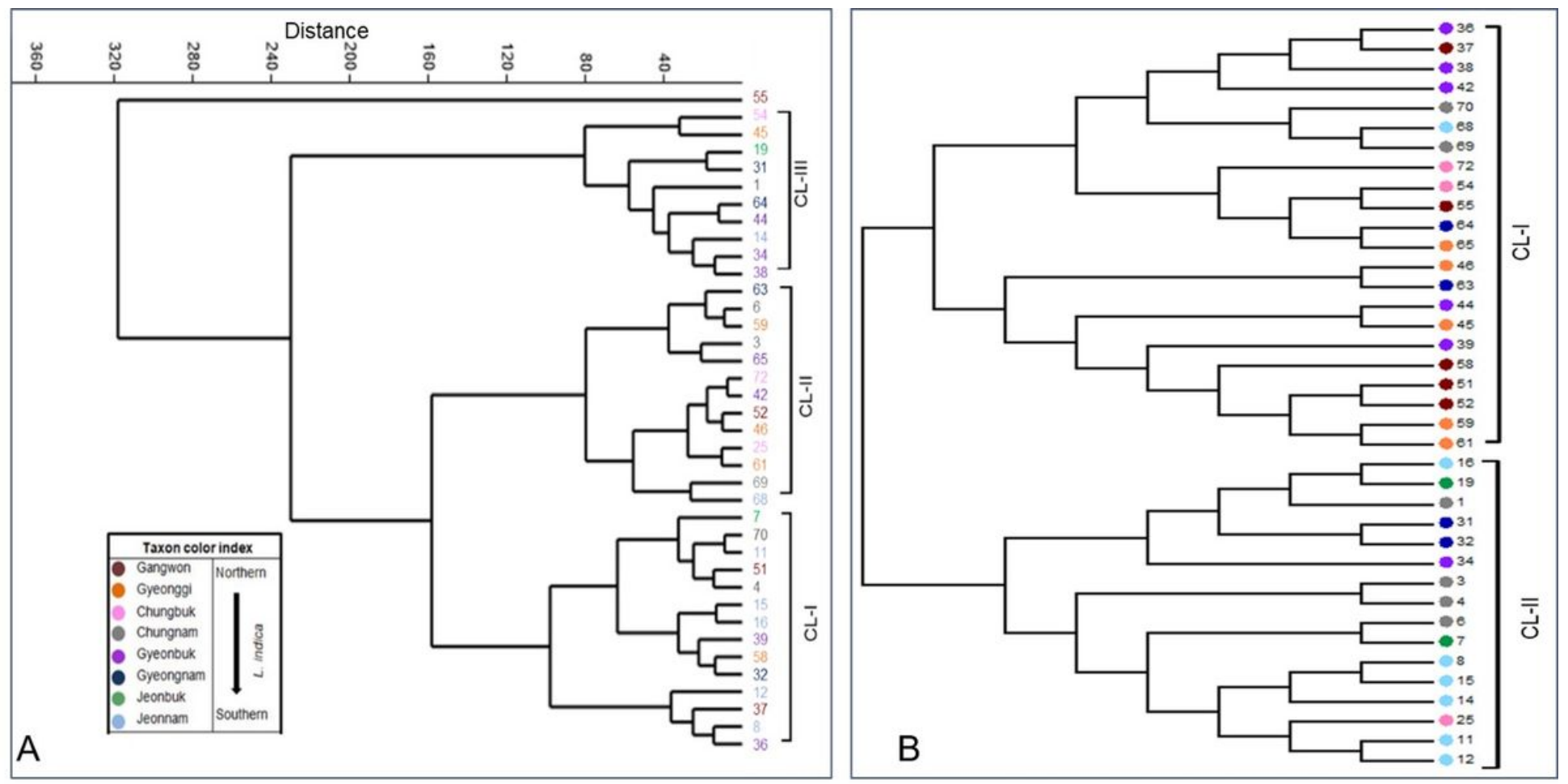

Figure 3

Principal component bi-plot showing distribution of accessions using nineteen morphological traits.

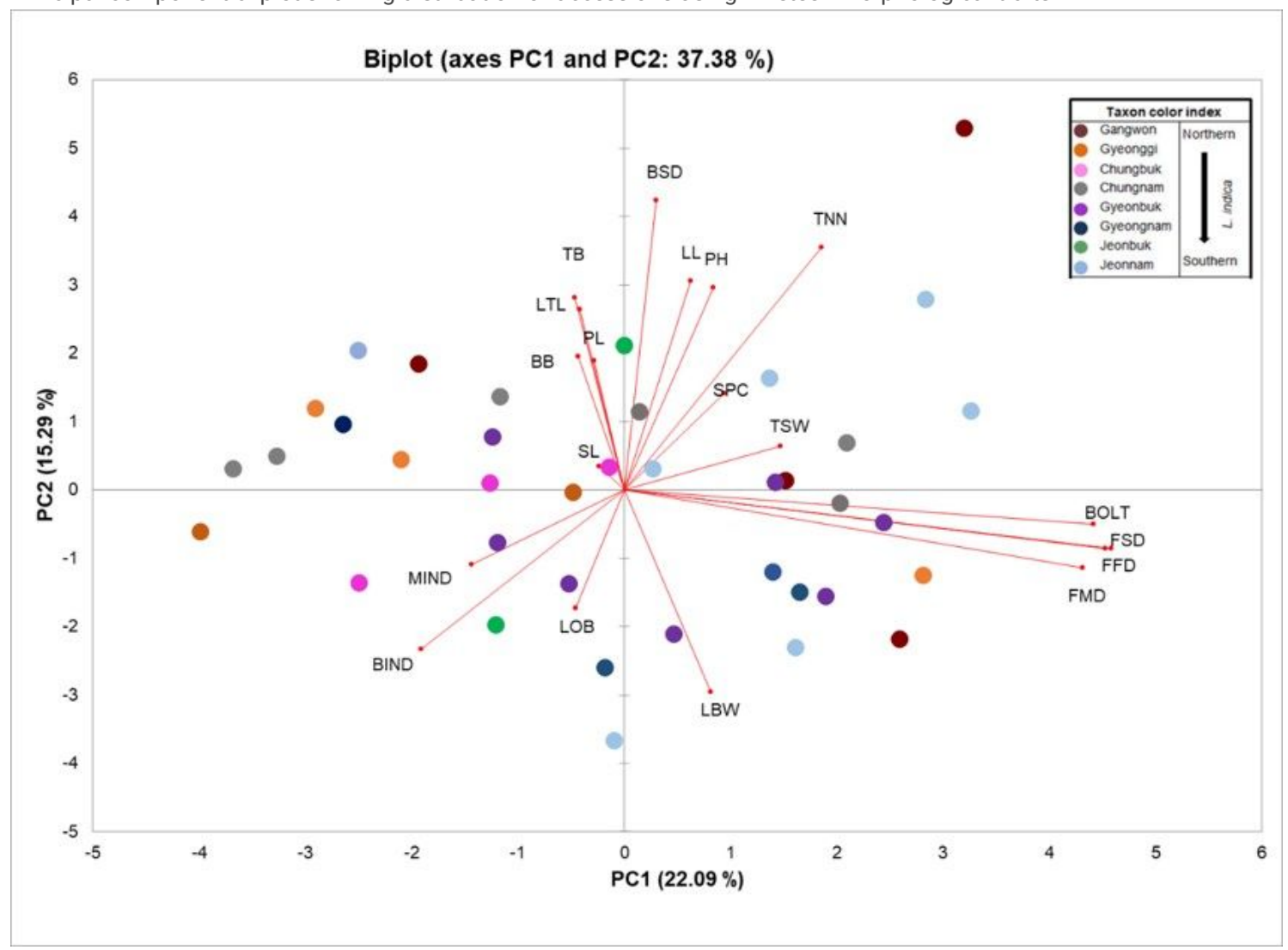

Figure 4

Phylogenetic relationship between 38 accessions of L. indica. A: Wards' phylogenetic tree using Euclidian distance matrix based on 19 morphological traits, B: UPGMA tree drawn using Nei's genetic distance of SSR genotyped data [obtained from Oliya et al. (2018)]. 
This is a list of supplementary files associated with this preprint. Click to download.

- MorphologymanuscriptsupplimantaryfilesJRCE.docx

Loading [MathJax]/jax/output/CommonHTML/fonts/TeX/fontdata.js 